\title{
Chemical Derivation to Enhance the Chemical/Oxidative Stability of Resorcinol-Formaldehyde (R-F) Resin
}
T.L. Hubler
W.J. Shaw
G.N. Brown
J.C. Linehan

\author{
J.A. Franz \\ T.R. Hart \\ M.O. Hogan
}

September 1996
Prepared for

the U.S. Department of Energy,

under Contract DE-AC06-76RLO 1830

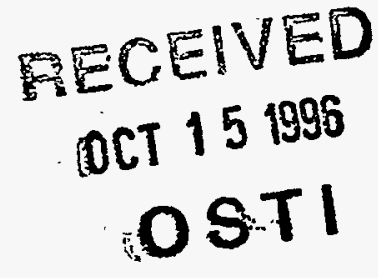

Pacific Northwest National Laboratory

Operated for the U.S. Department of Energy

by Battelle Memorial Institute

\section{\%}

EISTRIBUTION OF TH 


\title{
DISCIAIMER
}

This report was prepared as an account of work sponsored by an agency of the, United States Governiment. Neither the United States Government nor any agency thereof, nor Battelle Memorial Institute, nor, any of their employees, makes any warranty, express or implied, or assumes any legal liability or responsibility for the accuracy, completeness, or usefulness of any information, apparatus, product, or process disclosed, or represents that its use would not infringe privately owned rights. Reference herein to any specific commercial product, process, or service by trade name, trademark, manufacturer, or otherwise does not necessarily constitute or imply its endorsement, recommendation, or favoring by the United States Government or any agency thereof, or Battelle Memorial institute. The views and opinions of authors expressed herein do not riecessarily state or reflect those of the United States' Government or any agency thereot.

\author{
PACIFIC NORTHWEST NATIONAL" LABORATORY \\ operated by \\ BATTELLE MEMORIAL INSTITUTE \\ for thie \\ UNITED STATES DEPARTMENT OF ENERGY \\ under Contract DE-AC06-76RLO 1830
}

Printed in the United States of America

Available to DOE and DOE contractors from the

Office of Scientific and Technical Information, P.O. Box 62, Oak Ridge, TN 3783; prices available from (615) $576-8401$.

Available to the public from the National Technical Information Service,

U.S. Department of Commerce, 5285 Port Royal Rd., Springfield, VA 22161

This document was printed on recycled paper. 


\section{DISCLAIMER}

Portions of this document may be illegible in electronic image products. Images are produced from the best available original document. 


\title{
Chemical Derivation to Enhance the Chemical/Oxidative Stability of Resorcinol-Formaldehyde (R-F) Resin
}

\author{
T.L. Hubler \\ W.). Shaw \\ G.N. Brown \\ J.C. Linehan
}

J.A. Franz

T.R. Hart

M.O. Hogan

September 1996

\section{Prepared for}

the U.S. Department of Energy,

under Contract DE-AC06-76RLO 1830

Pacific Northwest National Laboratory

Richland, Washington 99352 


\section{Summary}

Tank wastes at the Hanford and Savannah River sites contain highly alkaline supernate solutions of concentrated sodium and potassium nitrates in which large amounts of the water-soluble radionuclide, ${ }^{137} \mathrm{Cs}$, are found. Economically, it is desirable to remove and concentrate the highly radioactive fraction of the tank wastes for vitrification, with the bulk of the waste being disposed of by a relatively low-cost method. This particular tank pretreatment need may be met using the appropriate ion-exchange technology and materials.

Resorcinol-Formaldehyde (R-F) resin is a candidate regenerable ion-exchange material which is being considered for use in the removal of radioactive cesium from alkaline waste tank supernates at both the Hanford and Savannah River sites. Structure/function studies of R-F resin performed at Pacific

Northwest National Laboratory showed that the chemical/ oxidative stability of R-F resin is an important issue under typical process conditions encountered for tank wastes and provided some possible solutions to this issue based on the structural chemistry of R-F resin.

This report summarizes studies into the synthesis and characterization of derivatized ResorcinolFormaldehyde (R-F) resins, which were prepared in pursuit of a more chemically/oxidatively robust R-F resin. The following specific conclusions and recomendations resulted from this study:

- Preparation of 4-methylresorcinol can be easily scaled up as long as the reactor equipment configuration does not allow the reactants to come into contact with any metal surfaces in the reactor; Teflon and glass liners are effective in this regard. The material is most easily purified using a short path distillation column under vacuum.

- Preparation of 4-fluororesorcinol can now be easily and safely prepared in large quantities using the electrophilic fluorinating agent, Selectfluor ${ }^{\mathrm{TM}}$ (Air Products, Inc.). Purification of this material from the difluororesorcinol byproduct will be most easily achieved using preparative scale HPLC.

- Curing temperatures for the 4-derivatized resorcinol resins should be elevated over the standard condition of $105^{\circ} \mathrm{C}$, which is used for R-F.resin. The 4-methylresorcinol formaldehyde resin shows that increased temperature induces further condensation to occur within the resin without substantial increase in oxidation to ketone and quinone structures. Indeed, the opposite trend is observed for those functionalities. However, R-F resin itself has essentially no ketone or quinone structures present when freshly prepared, in contrast to the 4-methylresorcinol polymer.

- The issue of crosslinking of the 4-derivatized resins with respect to their performance is an area of great importance for future study. Currently, it has not been possible to prepare methyl deriviatives which will not dissolve in water and/or $2 \mathrm{MNaOH}$ solution. NMR studies indicate that the methyl materials are oligomeric and that addition of phenolic moieties which can aid crossilinking is warranted. However, the additional amounts of crosslinking phenolic required may cause serious reduction in either capacity or chemical stability of the resin, hence in the performance of these resins. 
- The $85 \%$ 4-fluororesorcinol $/ 15 \%$ phenol formaldehyde resin appears to have good stability in alkaline solution, but elemental analysis results suggest there may be some nucleophilic displacement reaction which occurs during synthesis. Further studies should focus on a more thorough examination and correlation of structure and performance for this material. The related halogen material, 4-chlororesorcinol, also appears to undergo a nucleophilic displacement reaction of the chlorine, to give an oxidized organic and free chloride ion. 


\section{Acronyms}

APTI Advanced Processing Technology Initiative

CP-MAS cross polarization/magic angle spinning

DSSF double-shell slurry feed

ESP Efficient Separations and Processing Crosscutting Program

FTIR Fourier Transform Infrared

IR infrared

NMR nuclear magnetic resonance

P-F phenol-formaldehyde

PNNL Pacific Northwest National Laboratory

R-F resorcinol-formaldehyde

TGA-IR thermogravimetric analysis/infrared 



\section{Acknowledgments}

This project was funded by the U.S. Department of Energy, Office of Science and Technology under the Efficient Separations and Processing (ESP) Crosscutting Program. The authors gratefully acknowledge the data provided for this report from the experiments and analyses conducted by the following Pacific Northwest National Laboratory staff members: Rick J. Orth and George S. Deverman for autoclave reactions; and Jaquetta $\mathrm{R}$. Deschane for performing the $\mathrm{K}_{\mathrm{d}}$ analysis. Researchers at the University of Idaho, Department of Chemistry, are also acknowledged for their contributions to the synthetic challenges associated with the fluorinated resins: Professor Jean'ne M. Shreeve, Dr. Debao Su, and Dr. Jing Jing Yang. 



\section{Contents}

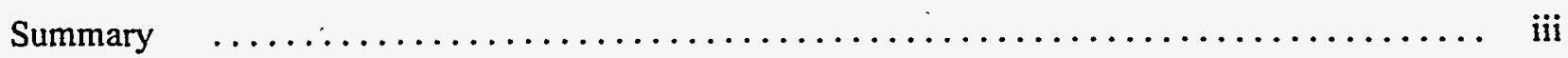

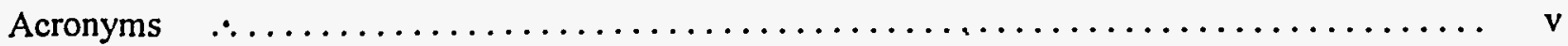

Acknowledgments $\ldots \ldots \ldots \ldots \ldots \ldots \ldots \ldots \ldots \ldots \ldots \ldots \ldots \ldots \ldots \ldots \ldots \ldots \ldots \ldots \ldots \ldots \ldots \ldots \ldots$

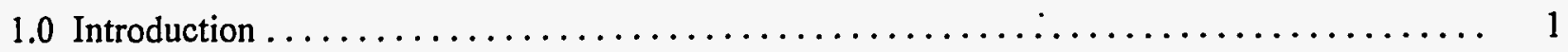

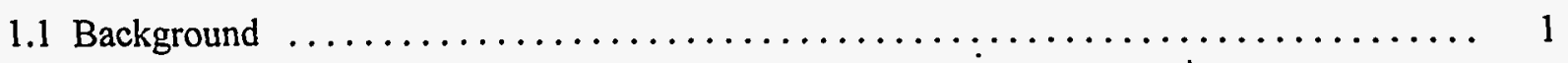

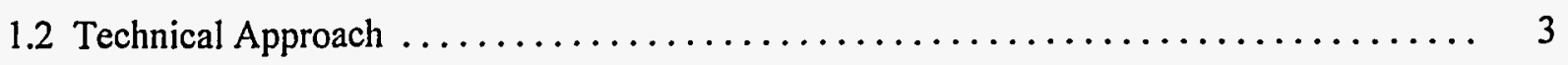

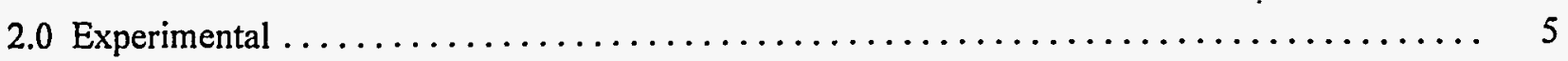

2.1 Preparation of Resins $\ldots \ldots \ldots \ldots \ldots \ldots \ldots \ldots \ldots \ldots \ldots \ldots \ldots \ldots \ldots \ldots \ldots \ldots$

2.2 Nuclear Magnetic Resonance Spectroscopy $\ldots \ldots \ldots \ldots \ldots \ldots \ldots \ldots \ldots \ldots \ldots$

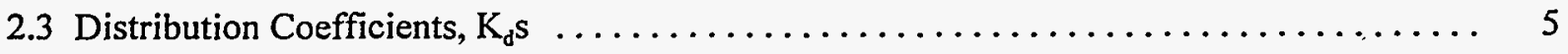

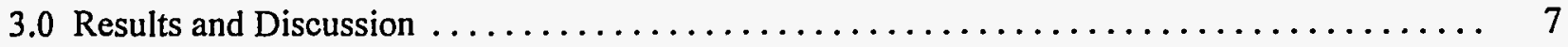

3.1 Preparàtion of Starting Materials $\ldots \ldots \ldots \ldots \ldots \ldots \ldots \ldots \ldots \ldots \ldots \ldots \ldots \ldots \ldots$

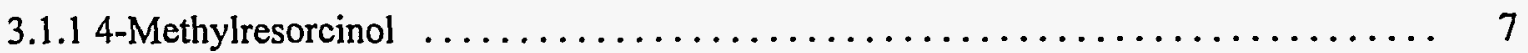

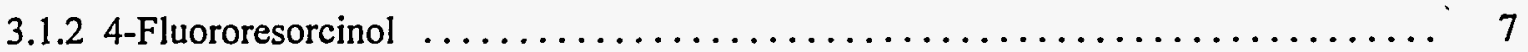

3.2 Preparation and Characterization of New R-F Resin Derivatives $\ldots \ldots \ldots \ldots \ldots \ldots \ldots$

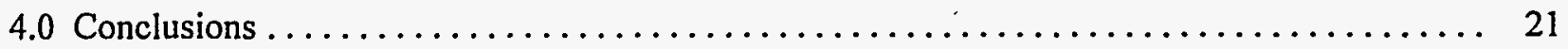

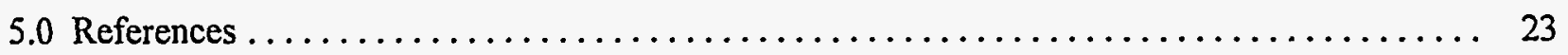




\section{Figures}

1 Resorcinol and ring numbering scheme $\ldots \ldots \ldots \ldots \ldots \ldots \ldots \ldots \ldots \ldots \ldots \ldots \ldots \ldots \ldots \ldots \ldots$

2 Oxidation of R-F resin gives para-quinones and loss of ion-exchange groups $\ldots \ldots \ldots \ldots$

3 Synthesis of P-F resins gives product with about $55 \%$ of the hydroxyl units etherified ...... 3

4 Preparation scheme for 4 -methylresorcinol $\ldots \ldots \ldots \ldots \ldots \ldots \ldots \ldots \ldots \ldots \ldots \ldots \ldots$

5 Preparation of 4-fluororesorcinol using reactive electrophilic fluorinating agents $\ldots \ldots \ldots . .8$

6 Alternative route for preparation of 4-fluororesorcinol using non-specialized reagents $\ldots \ldots \ldots \quad 8$

7 Facile preparation of 4 -fluororesorcinol using Selectfluor ${ }^{\mathrm{TM}} \ldots \ldots \ldots \ldots \ldots \ldots \ldots \ldots \ldots$

8 Potential synthetic route to 4 -trifluoromethylresorcinol $\ldots \ldots \ldots \ldots \ldots \ldots \ldots \ldots \ldots$

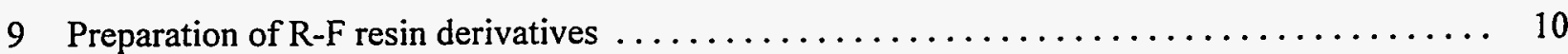

$10{ }^{13} \mathrm{C} \mathrm{CP-MAS} \mathrm{NMR} \mathrm{spectrum} \mathrm{of} 2$-methylresorcinol $\ldots \ldots \ldots \ldots \ldots \ldots \ldots \ldots \ldots \ldots$

$11{ }^{13} \mathrm{C}$ CP-MAS NMR spectrum of 2 -methylresorcinol formaldehyde resin $\ldots \ldots \ldots \ldots \ldots \ldots$

$12{ }^{13} \mathrm{C}$ CP-MAS NMR spectrum for 4 -methylresorcinol $\ldots \ldots \ldots \ldots \ldots \ldots \ldots \ldots \ldots \ldots \ldots \ldots$

$13{ }^{13} \mathrm{C} \mathrm{CP-MAS} \mathrm{NMR} \mathrm{spectrum} \mathrm{for} \mathrm{4-methylresorcinol} \mathrm{formaldehyde} \mathrm{resin} \ldots \ldots \ldots \ldots \ldots \ldots$

$14{ }^{13} \mathrm{C}$ CP-MAS NMR spectrum for 4-methylresorcinol cured for $20 \mathrm{~h}$ at $105^{\circ} \mathrm{C}$, then heat cured for (a) $4 \mathrm{~h}$ at $150^{\circ} \mathrm{C}$, and (b) $4 \mathrm{~h}$ at $200^{\circ} \mathrm{C} \ldots \ldots \ldots \ldots \ldots \ldots \ldots \ldots \ldots$

15 Heat treatment of 4-methylresorcinol formaldehyde resin leading to condensation of benzylic alchohol groups with other aromatic rings with consequent loss of water $\ldots \ldots \ldots \ldots \ldots \ldots \ldots \ldots$

16 Solution ${ }^{13} \mathrm{C}$ NMR of 4 -methylresorcinol in $\mathrm{D}_{2} \mathrm{O}^{\circ} \ldots \ldots \ldots \ldots \ldots \ldots \ldots \ldots \ldots \ldots \ldots \ldots$

17 Solution ${ }^{13} \mathrm{C}$ NMR of 4-methylresorcinol formaldehyde resin dissolved in $\mathrm{D}_{2} \mathrm{O} \ldots \ldots \ldots \ldots$

$18{ }^{13} \mathrm{C}$ CP-MAS NMR of $85 \%$ 4-methylresorcinol $/ 15 \%$ resorcinol formaldehyde resin $\ldots \ldots \ldots \ldots$

$19{ }^{13} \mathrm{C}$ CP-MAS NMR of $85 \%$ 4-methylresorcinol/15\% phenol formaldehyde resin $\ldots \ldots \ldots \ldots 18$

$20{ }^{13} \mathrm{C}$ CP-MAS NMR of $85 \%$ 4-fluororesorcinol $/ 15 \%$ phenol formaldehyde resin $\ldots \ldots \ldots \ldots 19$ 


\subsection{Introduction}

\subsection{Background}

Tank wastes at the Hanford and Savannah River sites contain highly alkaline supernate solutions of concentrated sodium and potassium nitrates in which large amounts of the water-soluble radionuclide, ${ }^{137} \mathrm{Cs}$, are found. Economically, it is desirable to remove and concentrate the highly radioactive fraction of the tank wastes for vitrification, with the bulk of the residual waste being disposed of as low-level waste by a relatively low-cost method. This particular tank pretreatment need may be met using the appropriate ion-exchange technology and materials. One candidate material for removing radiocesium from the tank wastes is resorcinol-formaldehyde (R-F) resin, an organic ion-exchange resin.

Initial evaluations (measured by determination of distribution coefficients, $\mathrm{K}_{\mathrm{d}} \mathrm{s}$ ) for different batches of R-F resin showed some variability in the performance of the resin; thus, there was a need to understand the structure of R-F resin and the important synthetic parameters that may affect the eventual performance of the product. Additionally, Duolite ${ }^{\mathrm{TM}} \mathrm{CS}-100$ (Rohm and Haas), a phenol-formaldehyde (P-F) resin, showed greater chemical stability but significantly less cesium selectivity than R-F resin. There was a need to understand the chemical nature of the performance differences for the two similar materials.

Structure/function studies for R-F resin were initiated at Pacific Northwest National Laboratory (PNNL) under the Advanced Processing Technology Initiative (APTI) in FY 94. These studies undertook preparation and characterization of R-F resin synthesized under a variety of conditions in order to establish the primary structure of the resin and to identify some of the important synthetic parameters critical for obtaining a quality ion-exchange product. ${ }^{1}$

The primary structural unit of R-F resin was found to be a 1,2,3,4-tetrasubstituted resorcinol ring (Figure 1). Both nuclear magnetic resonance (NMR) and infrared (IR) spectroscopic techniques provided direct evidence for this structure. Solid-state ${ }^{13} \mathrm{C}$ cross polarization/magic angle spinning (CP-MAS) NMR spectra for ${ }^{13} \mathrm{C}$ label-enhanced resin showed the presence of two non-equivalent methylene group carbons as expected for a 1,2,3,4-tetrasubstituted resorcinol ring. Fourier Transform Infrared (FTIR) structural analysis for R-F resin showed a primary band at $802 \mathrm{~cm}^{-1}$ corresponding to aromatic out-of-plane $\mathrm{C}-\mathrm{H}$ bending, which is indicative of the 1,2,3,4-tetrasubstituted ring pattern for the resorcinol unit. FTIR analysis also indicated the likely presence of some 1,2,4,5-tetrasubstituted

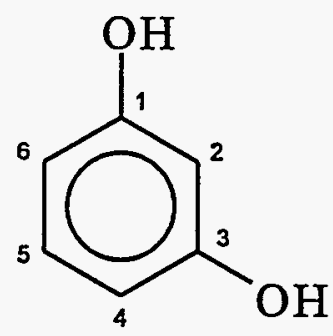

Figure 1. Resorcinol and ring numbering scheme 
and/or 1,2,4-trisubstituted resorcinol ring units, which comprise $15 \%$ or less of the polymer structure, by the presence of an IR band at $865 \mathrm{~cm}^{-1}$. Additionally, elemental analyses obtained for R-F resin in both the $\mathrm{H}^{+}$and $\mathrm{K}^{+}$forms were consistent with a 1,2,3,4-tetrasubstituted ring structure.

Some of the important synthetic parameters for R-F resin were investigated, including curing temperature and particle size. The curing temperature for R-F resin was found to be optimal between $105^{\circ} \mathrm{C}$ and $130^{\circ} \mathrm{C}$. Curing of resin below this temperature range results in insufficient crosslinking of the polymer resin. The result is that the ion-exchange performance of the resin is reduced because the lower crosslinked resin has much lower selectivity for cesium ion. An upper limit of $130^{\circ} \mathrm{C}$ for curing temperature is suggested because significant organic decomposition of the resin was observed at $135^{\circ} \mathrm{C}$ during thermogravimetric analysis/infrared (TGA/IR) analysis. Also, analysis of $\mathrm{K}_{d} \mathrm{~s}$ for $\mathrm{R}-\mathrm{F}$ resin cured at temperatures above $135^{\circ} \mathrm{C}$ in an inert helium atmosphere showed reduction of cesium $\mathrm{K}_{d} \mathrm{~s}$. The lower $\mathrm{K}_{\mathrm{d}} \mathrm{s}$ resulted from decomposition of the resin.

The effects of oxidation on R-F resins were elucidated by correlation of ${ }^{13} \mathrm{C}$ NMR spectra of the resins with their respective batch $\mathrm{K}_{d} s$. These studies showed that as oxidation of the resin takes place, quinone, ketone, and ether groups become prominent functionalities in the resin, along with a simultaneous drop in the number of phenolic hydroxyl ion-exchange groups.

The optimal particle size for the R-F resin to be used in an ion-exchange process was found to be in the range of 20-50 mesh sized particles. Particles larger than 20 mesh gave lower $K_{d} s$ because ion-exchange is diffusion limited in the larger particles. For particles smaller than 50 mesh, the greater surface area of the resin presented to the solution was more easily oxidized, or otherwise chemically degraded, with a concomitant loss of ion-exchange sites.

Modified polymers of P-F and R-F resins were prepared in order to better assess the factors affecting chemical stability. The polymer resins were modified by incorporating fluorophenols and hydroxybenzoic acids into the polymer matrix. The results led to an understanding of the observed structure/performance characteristics of the P-F resins in relation to R-F resin. It has been determined that both the R-F and P-F polymer resins are structurally similar with crosslinks in the 2- and 4- positions of the ring (see Figure 1). $\mathrm{R}-\mathrm{F}$ resin undergoes facile oxidation to form para-quinones (Figure 2) because the resorcinol ring is more activated toward oxidation (i.e., it is more electron rich) and there is a ring site readily available for oxidation that is para to a hydroxyl functionality. P-F resin (including CS-100), which has crosslinking similar to R-F resin, appears to be more chemically stable. This chemical stability arises because there is a less electron density present in the phenol aromatic ring and the position para to the hydroxyl function is generally alkylated (a methylene crosslinking group). Additionally, around $55 \%$ of the phenolic ring units are etherified during synthesis as determined by ${ }^{13} \mathrm{C}$ NMR studies (Figure 3), meaning that over half the theoretical ion-exchange capacity of the resin is lost during resin preparation. The $\mathrm{K}_{d} \mathrm{~s}$ for P-F resin are theoretically $50 \%$ that of R-F, but in actuality are closer to $5-10 \%$, largely due to the loss of ion-exchange sites that occurs as ring hydroxyl groups are etherified during preparation. 
<smiles>CCCC1=CC(=O)C(O)=C(CC)C1=O</smiles>

Figure 2. Oxidation of R-F resin gives para-quinones and loss of ionexchange groups<smiles>Oc1ccccc1</smiles><smiles>CC=O</smiles><smiles>CCCCc1cc(CC)ccc1OCC</smiles><smiles>CCc1ccc(O)c(CC)c1</smiles>

Figure 3. Synthesis of P-F resins gives product with about $55 \%$ of the hydroxyl units etherified

\subsection{Technical Approach}

The overall purpose of the Chemical Derivatization to Enhance Chemical Stability of R-F Resin task of the Efficient Separations and Processing (ESP) Crosscutting Program is to develop modified R-F resin(s) based on the structure/function relationships, which were determined during the FY 1994-95 APTI studies such that the chemical/oxidative stability of R-F resin is enhanced for conditions typically encountered in the remediation of cesium from alkaline radioactive tank wastes.

The technical approach includes design and synthesis of resorcinol derivatives, which are alkylated or otherwise functionalized, such that an aromatic ring carbon para to a ring hydroxyl group is more resistant to oxidation.

Both methyl and fluorine substituents are test cases for whether or not substitution at the positions para to the hydroxyl groups will slow or stop oxidation of the resorcinol ring to quinone structures and may provide further useful information about R-F structure/function relationships for design of other ionspecific ion-exchange resins. For the methyl group, the effect would presumably be primarily stearic, while thermodynamic bond strength considerations would be the primary effect for the fluorine substituent. The electronegative fluorine atom may remove enough electron density from the resorcinol 
ring such that oxidative susceptibility will be reduced without affecting the ion-exchange characteristics of the hydroxyl groups. A reduction of electron density in the resorcinol ring should decrease the likelihood of reaction with radical species and subsequent oxidation of the ring. 


\subsection{Experimental}

\subsection{Preparation of Resins}

Synthesis of the new resins is described below, and is similar to the procedure used for R-F resins in general. ${ }^{1,2}$ A typical procedure follows: 4-methylresorcinol, $37.2 \mathrm{~g}(0.30 \mathrm{~mole})$ was dissolved in $250 \mathrm{~mL}$ of deionized water in a $500 \mathrm{~mL}$ beaker. A $6 \mathrm{M} \mathrm{KOH}$ solution $(19.8 \mathrm{~g} 85 \% \mathrm{KOH}$ in $50 \mathrm{~mL}$ deionized water) was added to the stirring 4-methylresorcinol solution. The solution was heated and stirred for $1 \mathrm{~h}$ at $90^{\circ} \mathrm{C}$, then cooled to room temperature. Formalin $(87.5 \mathrm{~mL}$, Aldrich, $37 \%$ solution) was added all at once with stirring to the 4-methylresorcinol/KOH solution and stirred for an additional $10 \mathrm{~min}$. The whole mixture was poured into a pyrex baking dish (7" $x 12^{\prime \prime}$ ) and placed in a conventional oven at $105^{\circ} \mathrm{C}$ (oven was situated in a fume hood) for about $20 \mathrm{~h}$. The resulting resin was then ground using a disk mill and sieved to obtain 20-60 mesh particles. Some variations on the synthesis included preparation of $85 \%$ 4-methylresorcinol/15\% P-F resin, $85 \%$ 4-fluororesorcinol/ $15 \% \mathrm{P}-\mathrm{F}$ resin, and attempted preparations of the formaldehyde resins with 4-chlororesorcinol and 2-methylresorcinol. The curing temperatures and times were also varied.

\subsection{Nuclear Magnetic Resonance Spectroscopy}

Solution NMR spectra were obtained with the Varian Associates model VXR-300 spectrometer system and solid-state NMR spectra were obtained with a Chemagnetics model CMX-300/100 solid-state NMR spectrometer equipped with both Chemagnetics and Doty Scientific high-speed CP-MAS solid-state probes.

CP-MAS ${ }^{13} \mathrm{C}$ NMR spectra were obtained using $4.5 \mu \mathrm{s} 90^{\circ}$ proton pulses, 2 ms contact times and about $55 \mathrm{kHz}$ high power decoupling amplitudes with two-second recycle delays. Spectra were collected at $12 \mathrm{kHz}$ MAS speeds, necessitating an offset of the carbon matching amplitude by $12 \mathrm{kHz}$ from the static Hartman-Hahn match. During data acquisition, a fluorine decoupling frequency of about $55 \mathrm{kHz}$ field strength was used.

\subsection{Distribution Coefficients, $K_{d} s$}

The batch distribution coefficient $\left(\mathrm{K}_{\mathrm{d}}=[\mathrm{Cs}]_{\text {solid }} /[\mathrm{Cs}]_{\text {liquid }}\right)$ is an equilibrium measure of the ability of the solid phase ion-exchange material to remove an ion from solution. For the cesium $\mathrm{K}_{\mathrm{d}}$ tests described in this report, $0.1 \mathrm{~g}$ of the resin sample (normally the $\mathrm{K}^{+}$-form) was placed into standard $20-\mathrm{mL}$ scintillation vials and contacted with $15 \mathrm{~mL}$ of the $3.9 M \mathrm{Na}$ double-shell slurry feed (DSSF) waste simulant for $72 \mathrm{~h}$. The feed solution was radiolabeled by addition of approximately $12 \mathrm{nCi} / \mathrm{mL}{ }^{137} \mathrm{Cs}$. Cesium concentrations were determined by gamma counting. ${ }^{3}$ $\mathrm{K}_{\mathrm{d}} \mathrm{s}(\mathrm{mL} / \mathrm{g})$ were determined by measuring the analyte concentration in solution before and after contact and calculating the quantity of analyte on the adsorbent by difference, using the relationship 


$$
\mathrm{K}_{\mathrm{d}}=\frac{\left(\mathrm{C}_{\mathrm{i}}-\mathrm{C}_{\mathrm{f}}\right)}{\mathrm{C}_{\mathrm{f}}} * \frac{\mathrm{V}}{\mathrm{M} * \mathrm{~F}}
$$

where $C_{i}$ is the initial concentration of the ion of interest in the feed solution prior to contact, $C_{f}$ is the concentration after contact, $\mathrm{V}$ is the solution volume; $\mathrm{M}$ is the exchanger mass, and $\mathrm{F}$ is the mass of dry ion exchanger divided by the mass of wet ion exchanger. $K_{d}$ represents the theoretical volume of solution that can be processed per mass of exchanger under equilibrium conditions. Factor $\mathrm{F}$ was determined by drying the material at $105^{\circ} \mathrm{C}$ for $24 \mathrm{~h}$.

The composition of the double-shell slurry feed (DSSF) waste simulant is as follows:

$\begin{array}{ll}\text { Species } & \text { DSSF } M \\ & \\ \mathrm{Na}^{+} & 3.90 \mathrm{E}+00 \\ \mathrm{~K}^{+} & 9.23 \mathrm{E}-02 \\ \mathrm{Rb}^{+} & 8.57 \mathrm{E}-05 \\ \mathrm{Cs}^{+} & 7.00 \mathrm{E}-05 \\ \mathrm{Sr}^{2+} & 6.00 \mathrm{E}-07 \\ \mathrm{Al}^{3+} & 3.43 \mathrm{E}-01 \\ \mathrm{SO}_{4}{ }^{2-} & 1.19 \mathrm{E}-01 \\ \mathrm{HPO}_{4}{ }^{2-} & 1.98 \mathrm{E}-02 \\ \mathrm{OH}^{-} \text {(free) } & 1.32 \mathrm{E}+00 \\ \mathrm{OH}^{-} \text {(total) } & 4.08 \mathrm{E}+00 \\ \mathrm{CO}_{3}{ }^{2-} & 1.58 \mathrm{E}-01 \\ \mathrm{NO}_{2}{ }^{-} & 3.43 \mathrm{E}-01 \\ \mathrm{NO}_{3}- & 1.32 \mathrm{E}+00 \\ \mathrm{~F}^{-} & 7.05 \mathrm{E}-02\end{array}$

\subsection{Elemental Analyses.}

Elemental analyses for carbon and hydrogen were performed as combustion analyses using a PerkinElmer Model 240-B Elemental Analyzer. For the 4-fluororesorcinol-phenol formaldehyde resin, the following procedure was used to analyze both fluorine and potassium content. Some of the resin sample was pulverized for 30 seconds using a Wig-l-bug amalgamator apparatus. Approximately $0.1 \mathrm{~g}$ of the pulverized resin was placed on a tared filter paper and weighed. The sample was then washed through a 0.47 -micron filter with about $60 \mathrm{~mL}$ water. The resulting filtrate was placed in a $100 \mathrm{~mL}$ volumetric flask and adjusted to $100 \mathrm{~mL}$ by addition of water. A portion of the filtered solid was dried and weighed into a 20 -mL scintillation vial. Hydrogen peroxide $(30 \%, 5 \mathrm{~mL})$ was added and the vial left on a hot plate overnight at low heat to oxidize the organic resin. The contents were transferred to a $50 \mathrm{~mL}$ volumetric flask, the vial was rinsed several times into the flask, and water was added to the $50 \mathrm{~mL}$ calibration mark. The samples were analyzed for potassium ion using a Varian SpectrAA 800 spectrometer with air-acetylene flame and deuterium background correction. Fluoride ion analyses were performed using a Dionex DX-300 Ion Chromatograph equipped with a Dionex AS4A-SC 4-mm column and conductivity detector. The eluent used was $2.00 \mathrm{mMNaHCO} / 2.00 \mathrm{mMNa} \mathrm{NO}_{3}$. 


\subsection{Results and Discussion}

\subsection{Preparation of Starting Materials}

The route chosen to prepare the new resin derivative was to first derivativize the resorcinol ring, then polymerize it using formaldehyde. A description of the preparation of the starting materials follows.

\subsubsection{4-Methylresorcinol}

The 4-methylresorcinol was prepared using a previously known procedure. ${ }^{4}$ The reaction sequence involved hydrolysis of 2,4-diaminotoluene with ammonium bisulfate as shown in Figure 4. Initial batches were run in an Autoclave Engineers one-liter inconel autoclave, which was equipped with a glass liner, stainless steel thermowell, stainless steel thermocouple, and an inconel stirrer. There was noticeable etching on the stirrer and during the course of the reaction, substantial amounts of methane and carbon dioxide were produced. All subsequent batches were performed with the stirrer removed and the thermocouple and thermowell were lined with Teflon to prevent decomposition of the metal surface. After several successful batches in the one-liter autoclave, the production was scaled up to an Autoclave Engineers two-gallon stainless steel autoclave. It was determined that substantial decomposition will occur if the reaction solution comes into contact with any of the metal surfaces of the reactor, hence all equipment must be lined with glass or Teflon.

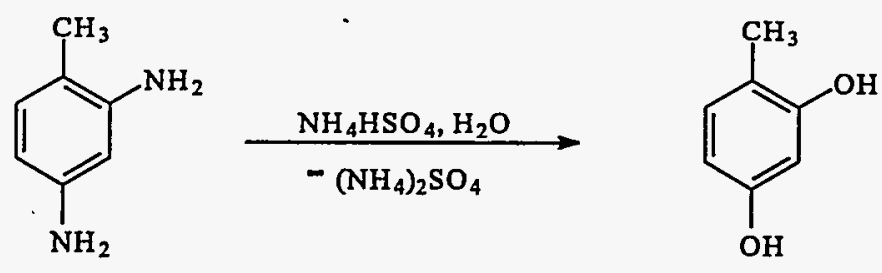

Figure 4. Preparation scheme for 4-methylresorcinol

In a typical preparation, $2160 \mathrm{~mL}$ of water was heated to $80^{\circ} \mathrm{C}$ in a $4 \mathrm{~L}$ beaker, followed by $1380 \mathrm{~g}$ of ammonium bisulfate was added and dissolved. Then $250 \mathrm{~g}$ of 2,4-diaminotoluene was added and dissolved in the hot solution, which was then poured into the glass liner of the reactor. After completing the autoclave setup, the reactor was heated to $230^{\circ} \mathrm{C}$ for $6-9 \mathrm{~h}$. Upon cooling, the contents of the reactor (a reddish liquid with some black solids) were removed and extracted using ethyl ether and water. The volume of the product-containing ether fraction was reduced using a rotary evaporator, and the viscous yellow colored solution was vacuum distilled at $113-117^{\circ} \mathrm{C}$. The short path distillation apparatus used was connected to a constant temperature circulating bath and the condenser solution was heated at $85^{\circ} \mathrm{C}$ to keep the solid product from condensing in the column, thereby clogging the distillation apparatus. The resulting distilled solid was crushed and used directly in the resin preparations.

\subsubsection{4-Fluororesorcinol}

Literature routes ${ }^{5}$ for preparation of 4-fluororesorcinol involve use of highly reactive electrophilic fluorinating agents such as fluoroxytrifluoromethane $\left(\mathrm{CF}_{3} \mathrm{OF}\right)$ and cesium fluoroxysulfate $\left(\mathrm{CsSO}_{4} \mathrm{~F}\right)$ as shown in Figure 5. For this reason, collaboration with fluorine researchers at the University of Idaho under the direction of Professor Jean'ne M. Shreeve was established to examine alternative routes to 4-fluororesorcinol and to aid in the synthesis should it be necessary to use the literature routes. The 
(i)<smiles>COc1cccc(OC)c1</smiles>

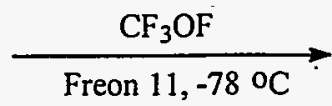<smiles>COc1ccc(F)c(OC)c1</smiles><smiles>CC(=O)O</smiles><smiles>Oc1ccc(F)c(O)c1</smiles>

(ii)<smiles>Oc1cccc(O)c1</smiles>

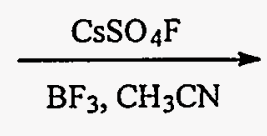<smiles>Oc1ccc(F)c(O)c1</smiles><smiles>Oc1cccc(O)c1F</smiles>

Figure 5. Preparation of 4-fluororesorcinol using reactive electrophilic fluorinating agents. Note that in (I), there is a mixture of difluoro and monofluoro products that must be . separated while in (ii) there is a mixture of monofluoro products.

major goal of their work was to find reagents, which could be safely and easily handled using standard benchtop procedures rather than the specialized equipment required for most fluorine syntheses.

One of the alternative routes initially explored for preparation of the 4-fluororesorcinol is shown in Figure 6. This scheme utilized 2,4-dinitrochlorobenzene as the starting material because it is a relatively inexpensive and easily obtained reagent. The chlorine substituent was metathesized with fluorine using potassium fluoride (KF) in $60-70 \%$ yield. In the second step, reduction of the nitro groups to amine groups could be effected, but in low yields $(\sim 30 \%)$ making this an undesirable route. ${ }^{6}$ The final hydrolysis of the fluorodiamine with either sulfuric acid and sodium nitrite or ammonium sulfate was never performed.

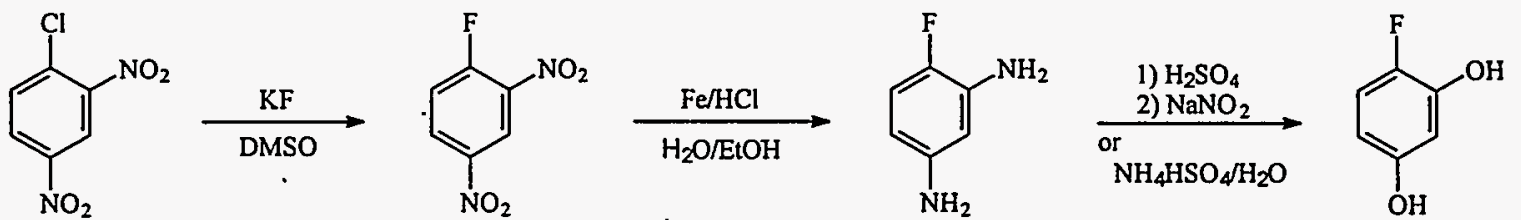

Figure 6. Alternative route for preparation of 4-fluororesorcinol using non-specialized reagents 
A better alternative to the reaction scheme shown in Figure 6 utilizes a new electrophilic fluorinating agent known as Selectfluor ${ }^{\mathrm{TM}}$ (1-chloromethyl-4-fluoro-1,4-diazoniabicyclo[2.2.2] octane), which is sold and distributed by Air Products and Chemicals, Inc. ,Allentown, PA. The reaction (Figure 7) is run at subambient temperature in a benchtop procedure and the reagent is easily weighed and handled in the air. The major difficulty encountered with this route to 4-fluororesorcinol is the difficulty in separating the monofluororesorcinol from the difluoro byproduct. It has been determined that the best yields are obtained using resorcinol rather than the protected methyl ether starting material (1,3-dimethoxybenzene), which also eliminates the need to undergo a further synthetic step. The reaction is run using acetonitrile as solvent with a temperature of $-5^{\circ} \mathrm{C}$ for $10 \mathrm{~h}$. The yield obtained under these conditions is $66 \% 4$-fluororesorcinol, $13 \%$ 2,6-difluororesorcinol, with the balance of the resorcinol unreacted. Purification has been effected using a chromatotron, but this method is inefficient, allowing only less than a gram of material to be purified in a single run. The separation problem can easily be addressed by preparative scale high performance liquid chromatography (HPLC) equipment.<smiles>Oc1cccc(O)c1</smiles>

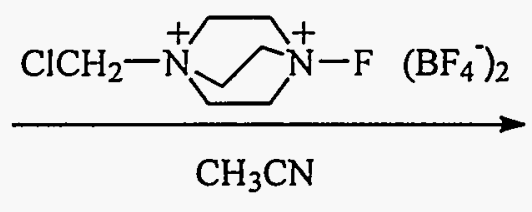<smiles>Oc1ccc(F)c(O)c1</smiles><smiles>Oc1cc(O)c(F)cc1F</smiles>

Figure 7. Facile preparation of 4-fluororesorcinol using Selectfluor ${ }^{\mathrm{TM}}$

In addition to the 4-fluororesorcinol, researchers at the University of Idaho are continuing development of . the 4-trifluoromethylresorcinol derivative. The scheme, shown in Figure 8, utilizes a route to the trifluoromethyldinitrobenzene compound ${ }^{7}$ followed by reduction of the nitro groups ${ }^{6}$ and subsequent hydrolysis of the resultant diamine. ${ }^{4}$ At this point in time, there are no commercially available electrophilic trifluoromethylating reagents.<smiles>Nc1ccc(C(F)(F)F)c(N)c1</smiles>

Figure 8. Potential synthetic route to 4-trifluoromethylresorcinol 


\subsection{Preparation and Characterization of New R-F Resin Derivatives}

The derivatized R-F resins were prepared using procedures previously established ${ }^{1}$ as shown in Figure 9. Attempts were made to form new resins from 4-chlororesorcinol, 4-fluororesorcinol, 2-methylresorcinol, and 4-methylresorcinol. The 4-chlororesorcinol and 2-methylresorcinol were commercially available materials while 4-fluororesorcinol and 4-methylresorcinol were prepared as described in the above sections.<smiles>[R]c1ccc(O)cc1O</smiles>
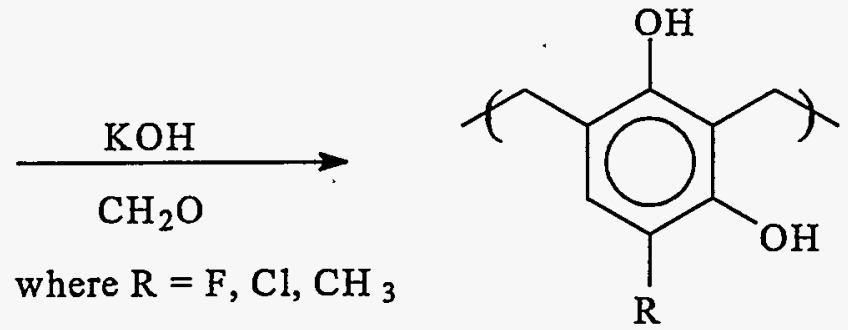

Figure 9. Preparation of R-F resin derivatives

During the reaction sequence with the 4-chlororesorcinol and potassium hydroxide, there appeared to be some precipitate formation after cooling of the solution. Upon curing of the mixture obtained with formaldehyde, there was a brown powder produced, hence polymer formation seemed unlikely. Analysis of the powder with ion-chromatography (IC) was accomplished first by washing a known amount of the material with water, then analyzing for chloride content in the water wash. This analysis showed that $13.5 \%$ of the sample was composed of free chloride ion (theoretical organochlorine is $16.69 \%$ based on a $\mathrm{C}_{7} \mathrm{H}_{6} \mathrm{ClO}_{3} \mathrm{~K}$ ) meaning that about $80 \%$ of the chlorine had been displaced from the starting material as chloride ion. Carbon and hydrogen combustion analysis of the washed solid gave $42.92 \% \mathrm{C}$ and $2.92 \% \mathrm{H}$, which differed from the theoretical values of $39.52 \% \mathrm{C}$ and $2.84 \% \mathrm{H}$. It would be expected that the $\mathrm{C}$ and $\mathrm{H}$ analyses would be high if a significant amount of chlorine was lost from the organic as chloride ion. This material was not explored further because of the great decomposition it showed.

A sample of 2-methylresorcinol formaldehyde resin was prepared using typical conditions for preparation of R-F resin, yet a normal resin did not form as expected and gave a dark brown powdery material which was water soluble. The ${ }^{13} \mathrm{C}$ CP-MAS NMR spectrum of the 2-methylresorcinol starting material and formaldehyde polymer are shown in Figure 10 and Figure 11, respectively. The spectrum indicates that there is unreacted 2-methyl resorcinol in the sample by the presence of resonances at 10 and $157 \mathrm{ppm}$ (appears as a shoulder in the polymer). Additionally, the spectrum shows that there is substantial residual formaldehyde (resonance at $172 \mathrm{ppm}$ ) and ketone/quinone functionalities at 195 and $180 \mathrm{ppm}$, respectively. The broad resonance at about $50 \mathrm{ppm}$ is probably indicative that benzylic alcohol groups are also present in this material. Higher curing temperatures may force condensation of the benzylic alcohol groups with other aromatic groups. 


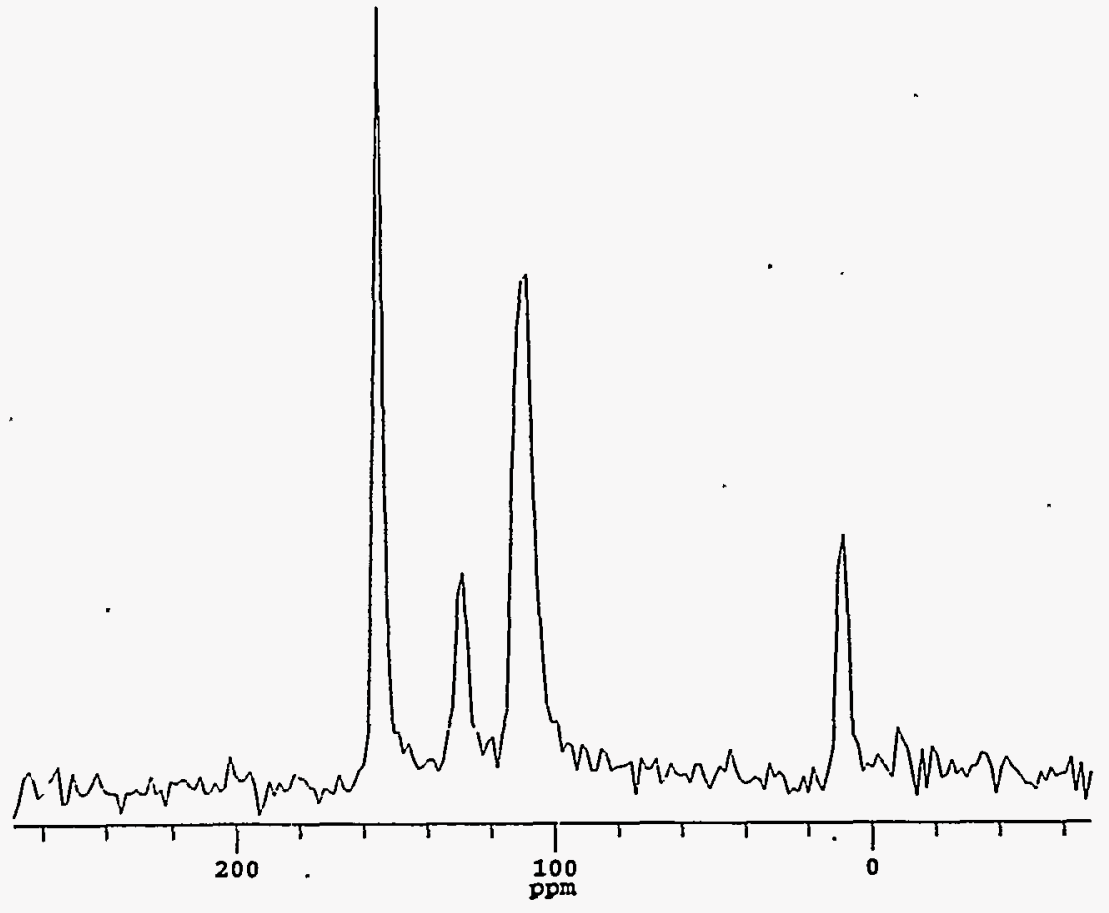

Figure 10. ${ }^{13} \mathrm{C}$ CP-MAS NMR spectrum of 2-methylresorcinol

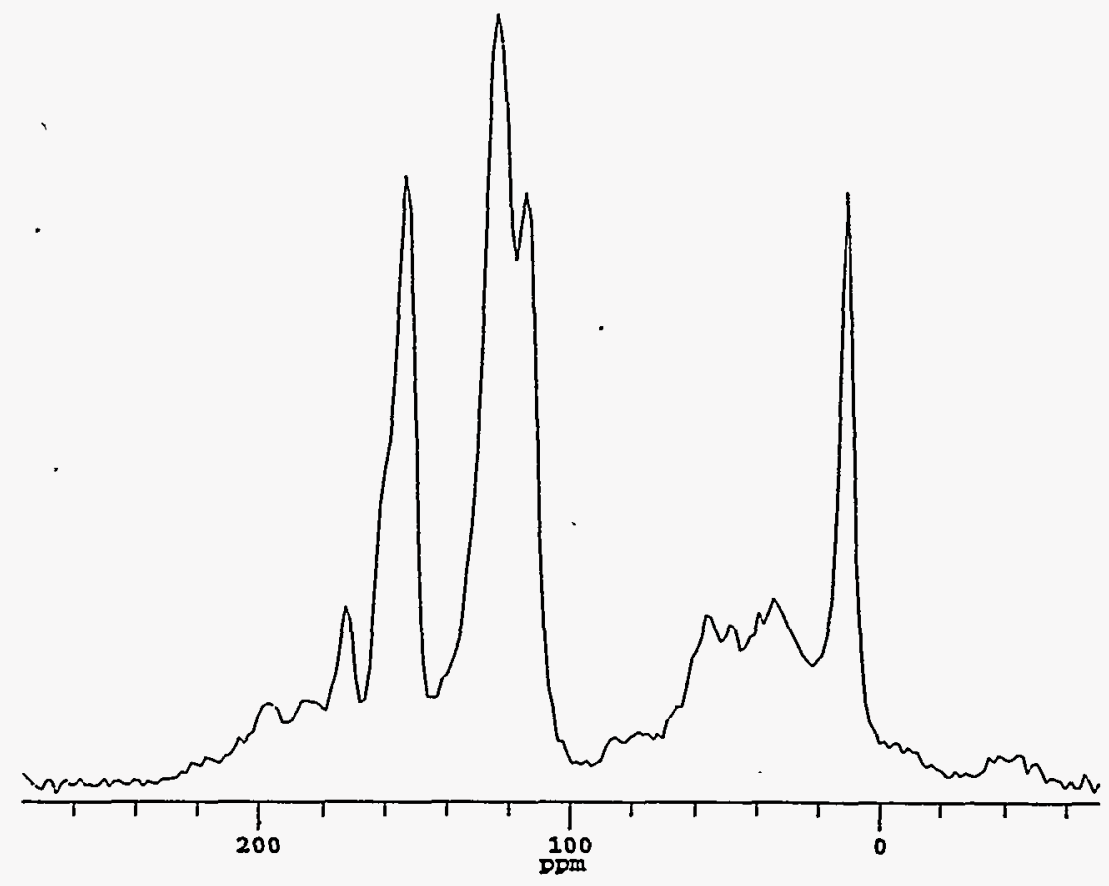

Figure 11. ${ }^{13} \mathrm{C}$ CP-MAS NMR spectrum of 2-methylresorcinol formaldehyde resin 
The ${ }^{13} \mathrm{C} \mathrm{CP-MAS} \mathrm{NMR} \mathrm{spectrum} \mathrm{for} \mathrm{4-methylresorcinol} \mathrm{(Figure12)} \mathrm{shows} \mathrm{the} \mathrm{expected} \mathrm{six} \mathrm{resonances}$ with the following assignments: 152 ppm (C-1, C-3); 128 ppm (C-5); 114 ppm (C-4); 104 ppm (C-6); 98 ppm (C-2); $14 \mathrm{ppm}\left(\mathrm{CH}_{3}\right)$. In Figure 13, the comparable spectrum is shown for the resin prepared by reaction with formaldehyde under basic conditions using standard conditions for the synthesis. The polymer thus prepared was a dark opaque brown color with some lightly colored solid, and was therefore heterogeneous in appearance; this may indicate the presence of some unreacted starting material or potassium salt of the 4-methylresorcinol. In contrast, the usual appearance of R-F resin is a translucent red color. The sample had to be ground using the disk mill, and appeared to have reasonable strength. It also swelled in a similar fashion compared to R-F. Thus, when soaked in water, the volume of the wet resin compared to dry resin nearly doubled. However, the resin dissolves in $2 M \mathrm{NaOH}$ after $5 \mathrm{~h}$ of solution contact to give a dark red colored solution:

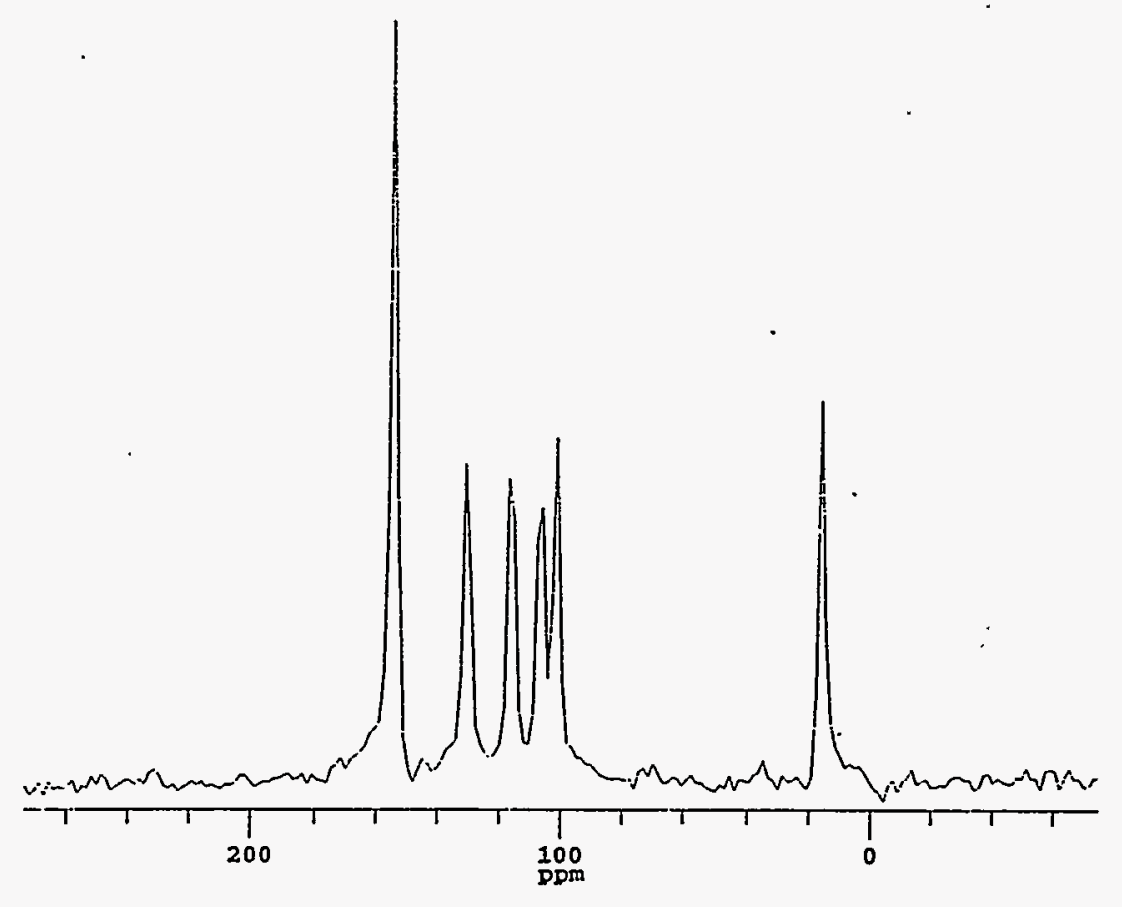

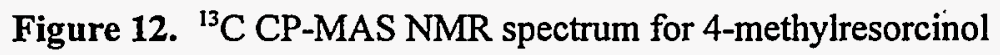

Initially, it was believed that there was little or no quinone functionality in the sample, but a substantial and nearly equal fraction of ketone (196 ppm) and quinone $(183 \mathrm{ppm})$ functionality can be seen for this material in the ${ }^{13} \mathrm{C}$ solid-state NMR (Figure 13). Additionally, there is a substantial amount of formaldehyde still incorporated in this sample as indicated by resonance at $172 \mathrm{ppm}$, and benzylic resonance appears around $45-50 \mathrm{ppm}$. The broad resonance.centered around $80 \mathrm{ppm}$ may be indicative of secondary alcoholic groups, which would be formed by alcoholic functionality on the methylene bridges. 


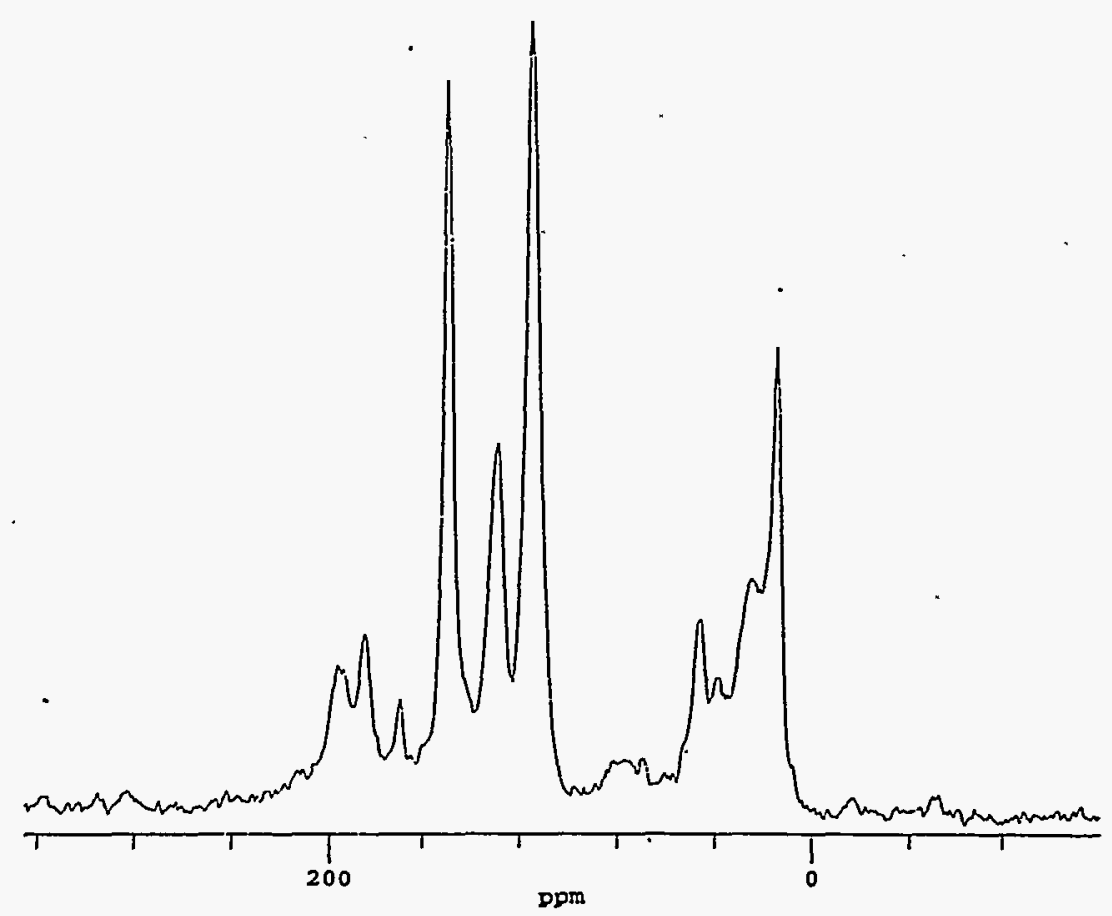

Figure 13. ${ }^{13} \mathrm{C}$ CP-MAS NMR spectrum for 4-methylresorcinol formaldehyde resin

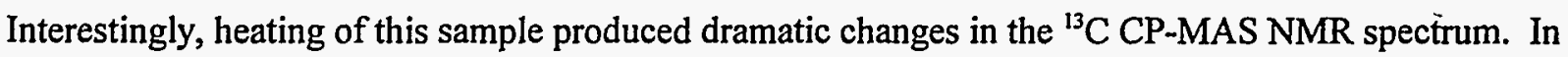
Figure 14(a), a sample of the 4-methylresorcinol formaldehyde resin, which had been cured for $20 \mathrm{~h}$ at $105^{\circ} \mathrm{C}$, was further heated in a sealed tube at $150^{\circ} \mathrm{C}$ for $4 \mathrm{~h}$. Significant benzylic carbon functionality and ketone/quinone resonances can be seen to decrease in intensity, while the sharper resonance for the methylene/methyl resonance region increases. Curing of another sample under similar conditions, but up to $200^{\circ} \mathrm{C}$ (Figure 14(b) shows even greater improvement in this trend. From the spectrum in Figure 14(b), it is apparent that there is still some quinone and ketone functionality remaining, but the amount has decreased significantly. Most of the benzylic carbon functionality has also disappeared. There are still small amounts of unreacted formaldehyde and secondary alcohol present in the sample. The conclusion from the heat treating experiments is that higher curing temperatures seem to force the condensation of the benzylic alcohol groups with other aromatic rings as pictured in Figure 15. Other full-scale preparations of 4-methylresorcinol formaldehyde resin at 150 and $174{ }^{\circ} \mathrm{C}$ for varying amounts of time gave similar NMR results; however, it was not possible to completely eliminate the presence of all the ketone, quinone, formaldehyde, and benzylic alchol groups from the resin samples using these conditions. Additionally, all of these resins would dissolve in water and/or $2 \mathrm{M} \mathrm{NaOH}$ solution. Some of the water soluble material was characterized using solution NMR. The ${ }^{13} \mathrm{C}$ liquid NMR spectrum of 4-methylresorcinol is shown in Figure 16 and is consistant with the solid spectrum in Figure 12. This observation led to exploration of the issue surrounding the crosslinking of the resin. 


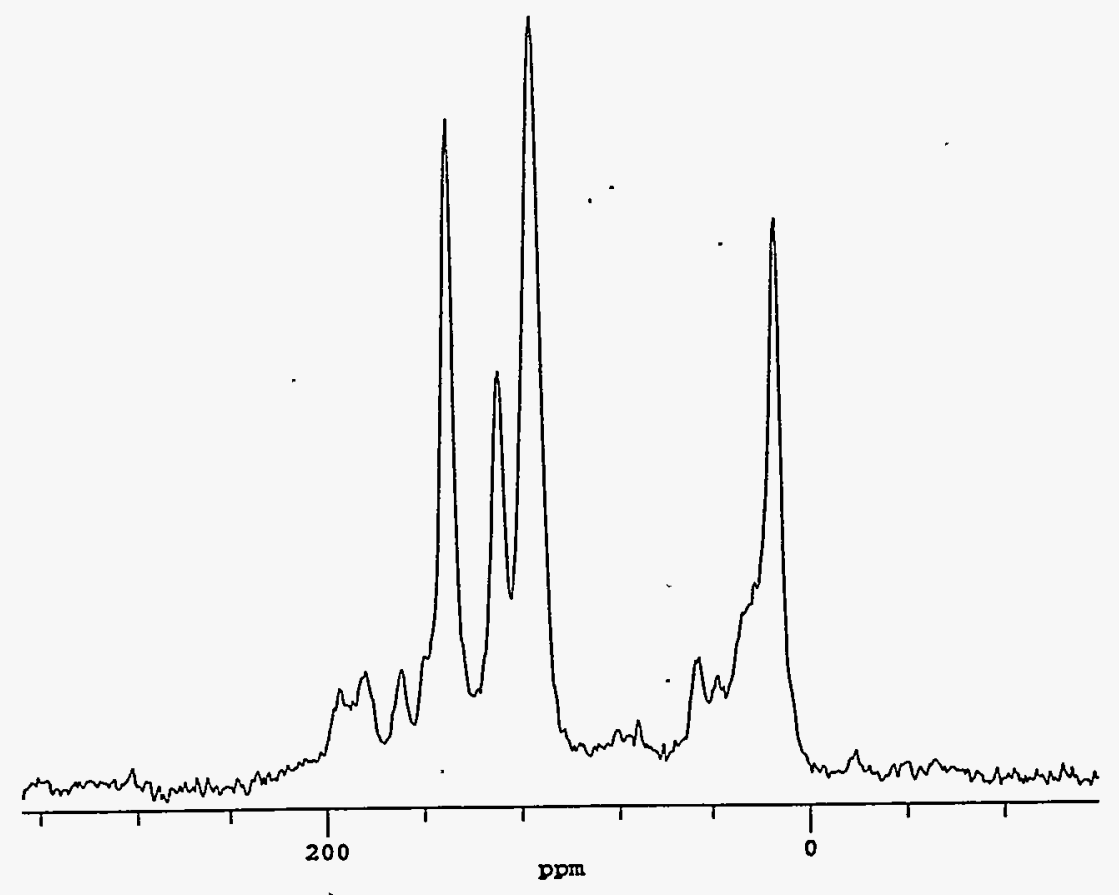

(a)

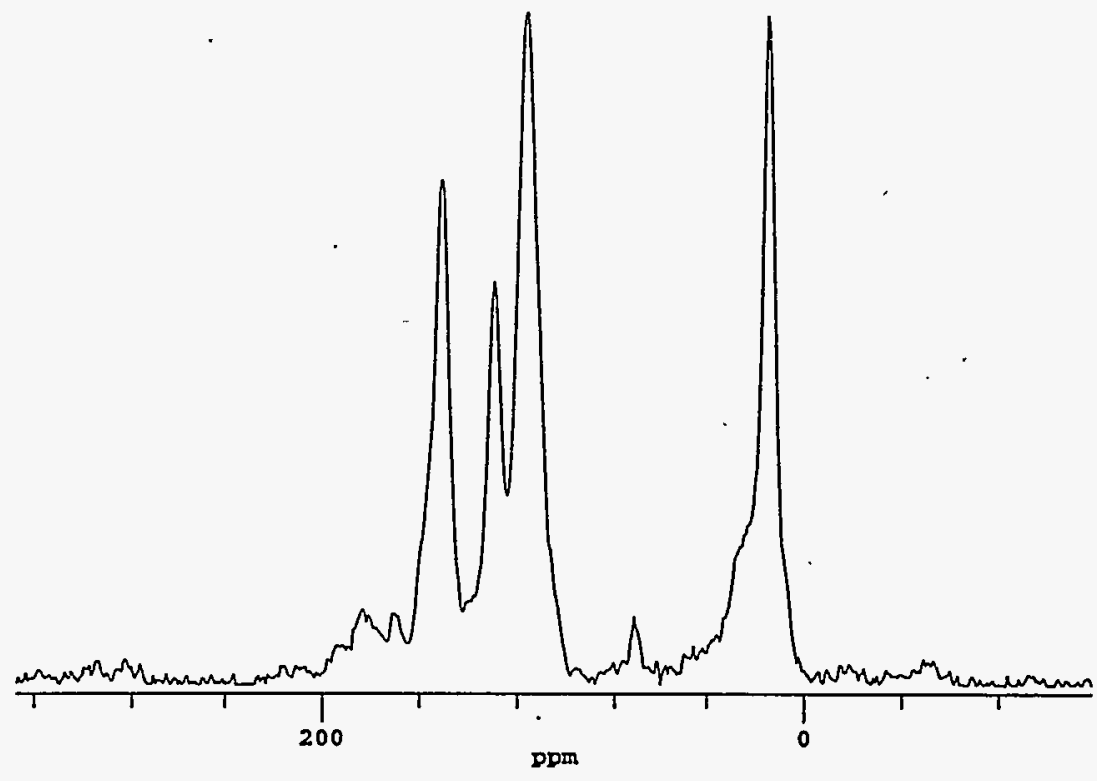

(b)

Figure 14. ${ }^{13} \mathrm{C} \mathrm{CP-MAS} \mathrm{NMR} \mathrm{spectrum} \mathrm{for} \mathrm{4-methylresorcinol} \mathrm{cured} \mathrm{for} 20 \mathrm{~h}$ at $105^{\circ} \mathrm{C}$, then heat cured for (a) $4 \mathrm{~h}$ at $150^{\circ} \mathrm{C}$, and (b) $4 \mathrm{~h}$ at $200^{\circ} \mathrm{C}$ 
<smiles>CCc1cc(C)c(O)cc1OC</smiles><smiles>CCc1cc(C)c(O)c(CO)c1[Cl+]</smiles>

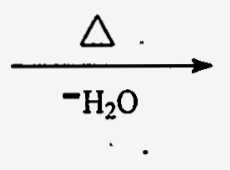<smiles>CCc1cc(C)c(O)c(Cc2cc(C)c(O)cc2[O+])c1[O+]</smiles>

Figure 15. Heat treatment of 4-methylresorcinol formaldehyde resin leading to condensation of benzylic alcohol groups with other aromatic rings followed by loss of water

NMR analysis of the water soluble 4-methylresorcinol formaldehyde resin material (Figure 17) indicates that the water soluble material is oligomeric in nature. The 4-methylresorcinol ring resonances have moved to lower fields in the case of C-2 and C-6, while C-5 has moved to a slightly higher field. The resonance for $\mathrm{C}-4$ remains at a relatively unchanged chemical shift $(117.5 \mathrm{ppm})$ as do the two unresolved resonances of the hydroxyl ipso ring carbons (155 ppm). Methylene group resonances are observed at $27-21 \mathrm{ppm}$. Presumably, there is also some of the ketone and quinone functionality present in the soluble organic, but it is not observed with the signal/noise level reached for this particular spectrum. Hence, it appears that the resin is oligomerizing (number of ring units is not yet known) and does crosslink at the 2- and 6-position of the 4-methylresorcinol ring as would be expected, but apparently there is little crosslinking of the oligomers or polymer strands. This observation led to further exploration of the issue surrounding the crosslinking of the resin.

Greater crosslinking of the polymer resin can be achieved by addition of either resorcinol or phenol to the 4-methylresorcinol because these aromatic systems have three sites that are activated towards substitution. It is known that the primary structural unit of R-F resin itself is the 1,2,3,4-tetrasubstituted ring, but about $10-15 \%$ of the $\mathrm{R}-\mathrm{F}$ resin may consist of pentasubstituted rings, which probably serve as the major crosslinks between the polymer strands. In the case of phenol, crosslinking positions occur at the 2-, 4-, and 6-positions of the ring and at the hydroxyl group as well (see Figure 6). For resorcinol, there is a theoretical increased susceptibility to chemical oxidation, while there is a theoretical loss of capacity if phenol is used as an agent to promote crosslinking. Both phenol and resorcinol containing 4-methylresorcinol formaldehyde resins were prepared in the ratio of $85 \%$ 4-methylresorcinol $/ 15 \%$ resorcinol or phenol. The resorcinol containing resin (Figure 18) appeared very similar to R-F resin itself, and swelling characteristics were similar, however, this resin also dissolved in $2 \mathrm{M} \mathrm{NaOH}$ after about 6-7 hours. For the phenol crosslinking experiment (Figure $19\left[{ }^{13} \mathrm{C} \mathrm{CP-MAS} \mathrm{NMR} \mathrm{of} 85 \%\right.$ 4-methylresorcinol/15\% phenol formaldehyde resin.]), again the NMR spectrum appears to be very similar to that of 4-methylresorcinol formaldehyde resin, but the resin was slightly more robust and required about $10 \mathrm{~h}$ of contact with $2 \mathrm{M} \mathrm{NaOH}$ solution to dissolve. Apparently the addition of phenol did have a beneficial effect on the crosslinking of the resin, but it is not clear yet where the balance between loss of capacity and increased chemical stability will fall for the combined material (4-methylresorcinol and phenol). 


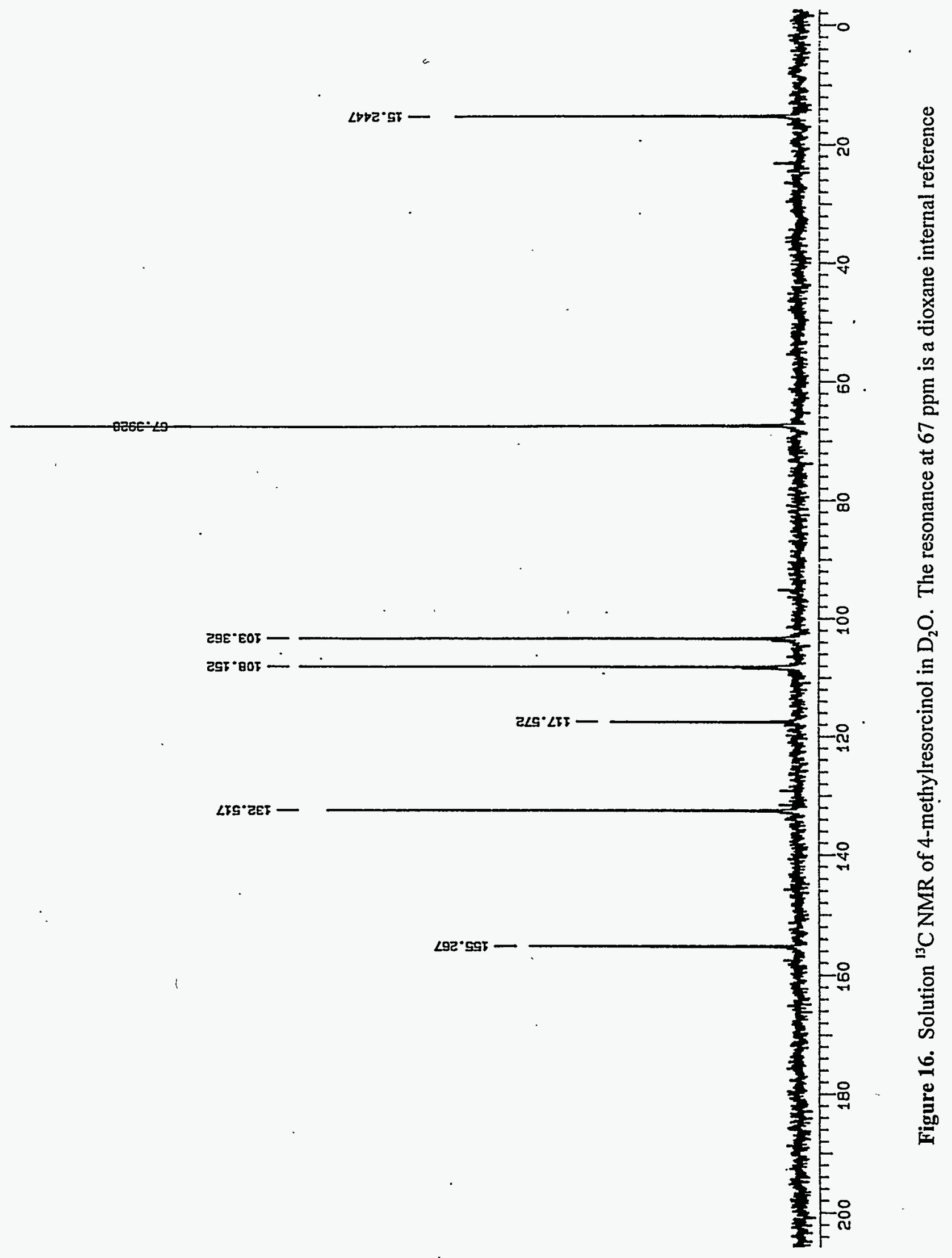




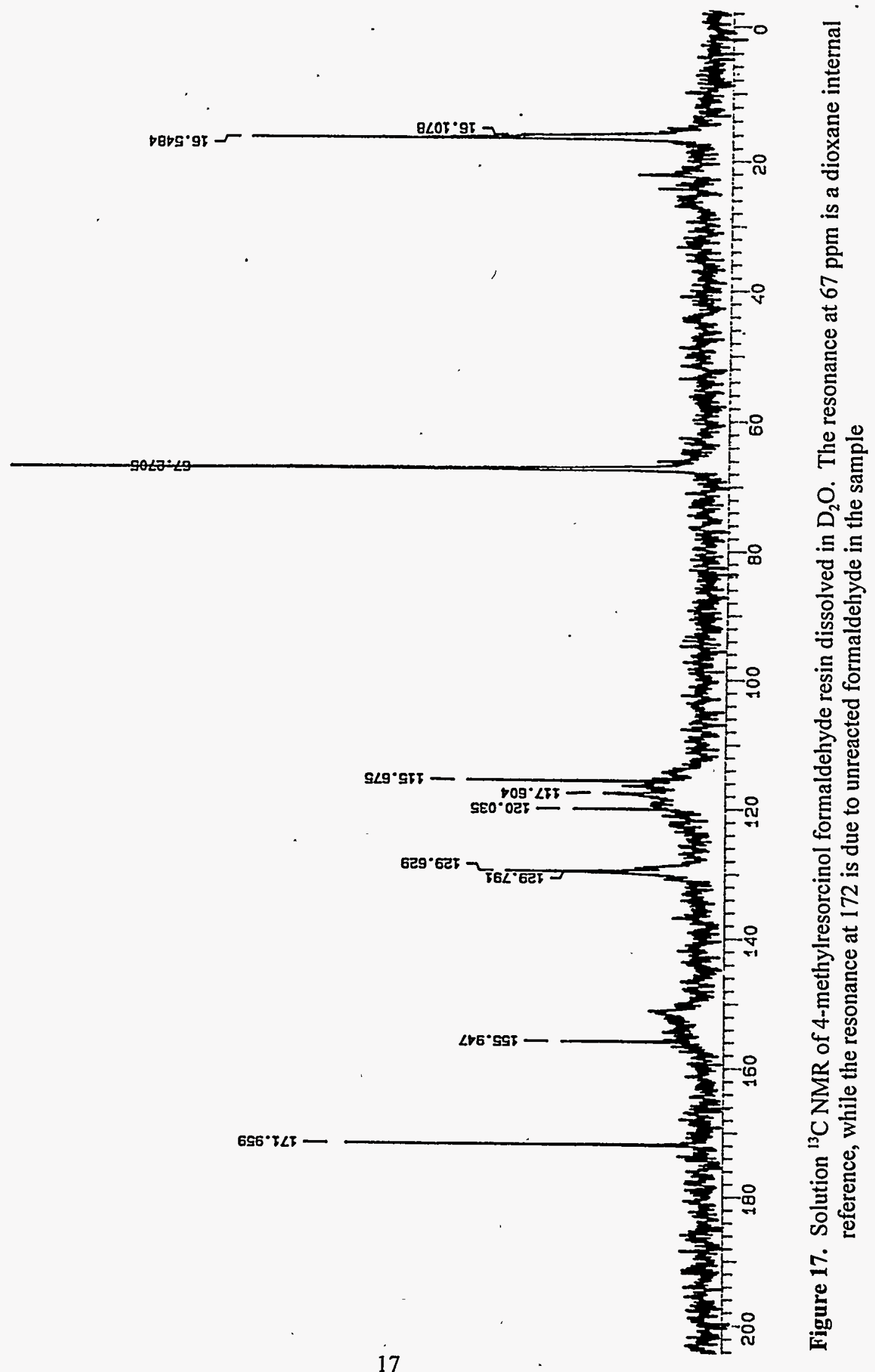




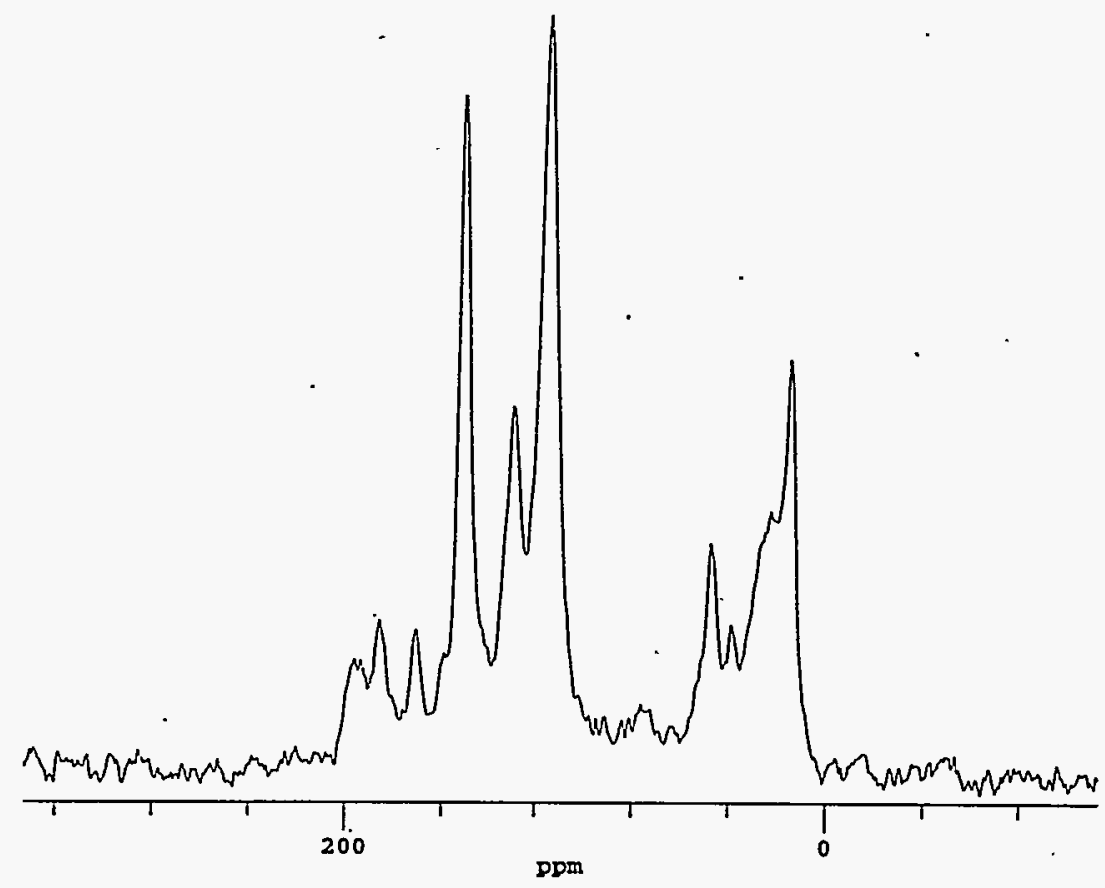

Figure 18. ${ }^{13} \mathrm{C}$ CP-MAS NMR of $85 \%$ 4-methylresorcinol/15\% resorcinol formaldehyde resin

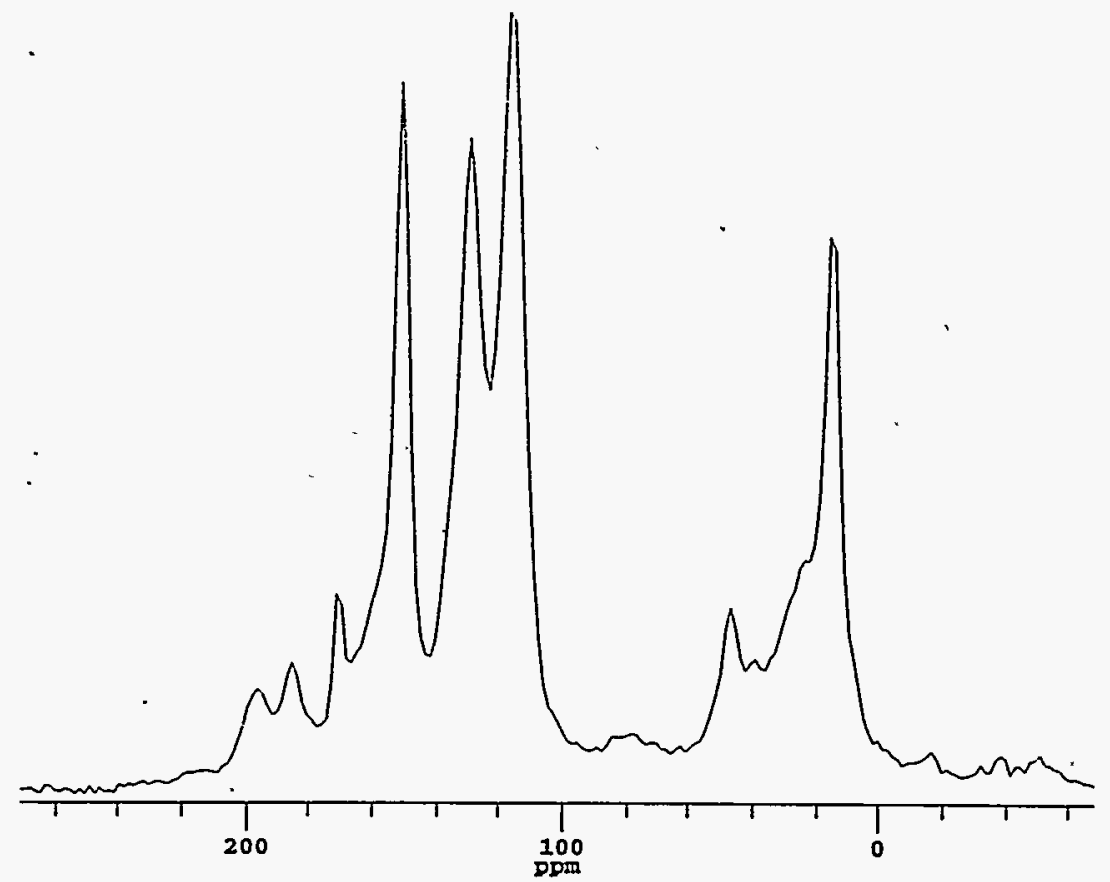

Figure 19. ${ }^{13} \mathrm{C} \mathrm{CP-MAS} \mathrm{NMR} \mathrm{of} 85 \%$ 4-methylresorcinol/15\% phenol formaldehyde resin 
A sample consisting of $85 \%$ 4-fluororesorcinol/15\% phenol formaldehyde resin was prepared using standard procedures, except the material was cured at $195^{\circ} \mathrm{C}$ for $20 \mathrm{~h}$. Phenol was added as a crosslinking agent to this material in view of the apparently poor results obtained with the methyl derivatives. The resin obtained was a hard black solid which did swell in water and $2 \mathrm{M} \mathrm{NaOH}$ solution, but did not dissolve even after 2 days in contact with the $\mathrm{NaOH}$ solution. Very little color was given off to the solution. The ${ }^{13} \mathrm{C}$ CP-MAS NMR of this resin is shown in Figure 20 and is unremarkable except for the rather large baseline roll and broad resonances, which may be indicative of high free radical content. The batch $\mathrm{K}_{\mathrm{d}}$ obtained for this resin was $86 \mathrm{~mL} / \mathrm{g}$, hence its performance was similar to P-F resin. It is not clear at this time if the reduced performance of this $\mathrm{R}-\mathrm{F}$ derivative is due to crosslinking, steric, electronic, or a combination of the above factors. The carbon and hydrogen combustion analyses for this material gave $42.54 \% \mathrm{C}$ and $4.22 \% \mathrm{H}$ compared to theoretical values of $43.60 \% \mathrm{C}$ and $3.19 \% \mathrm{H}$. Analysis for fluorine and potassium from a sample of deionized water contacted with this resin indicated that there was fluoride ion present within the resin matrix itself, suggesting that this resin also undergoes a nucleophilic displacement reaction similar to the 4-chlororesorcinol reaction. Hence, total fluorine content of the resin was $7.67 \%$ (theory is $8.51 \%$ ) and total potassium content was $12.97 \%$ (theory is $19.40 \%$ ). Of the total fluorine, $6.04 \%$ occurs as water soluble fluoride ion, or about $79 \%$ of the sample's fluorine is fluoride ion. The analytical results seem to indicate that 4-fluororesorcinol undergoes a similar decomposition reaction to its chlorine analog during synthesis, thus giving nearly $80 \%$ fluoride ion and low analyses for all other elements (which probably indicates greater incorporation of oxygen). However, the polymer produced appears to be fairly stable in alkaline solution, and does have ion-exchange performance for cesium which is similar to P-F resin.

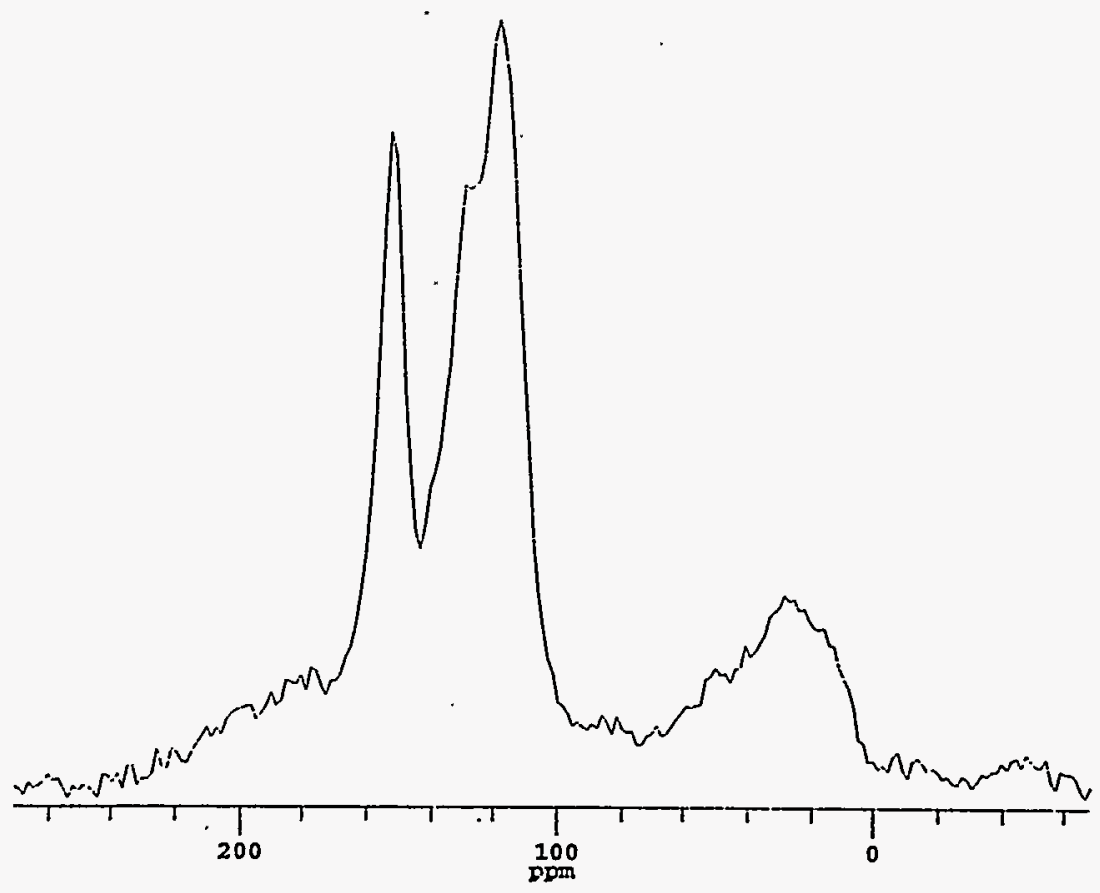

Figure 20. ${ }^{13} \mathrm{C}$ CP-MAS NMR of $85 \%$ 4-fluororesorcinol/15\% phenol formaldehyde resin 


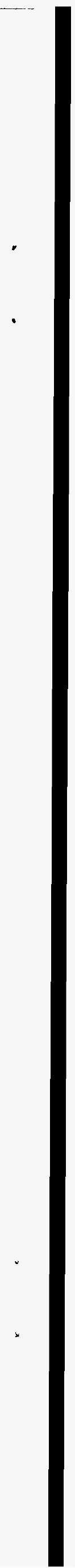




\subsection{Conclusions}

Preparation of 4-methylresorcinol can be easily scaled up as long as the reactor equipment configuration does not allow the reactants to come into contact with any metal surfaces in the reactor; Teflon and glass liners are effective in this regard. The material is most easily purified using a short path distillation column under vacuum.

Preparation of 4-fluororesorcinol can now be easily and safely prepared in large quantities using the electrophilic fluorinating agent Selectfluor ${ }^{\top M}$ (Air Products, Inc.). Purification of this material from the difluororesorcinol byproduct will be most easily achieved using preparative scale HPLC.

Curing temperatures for the 4-derivatized resorcinol resins should be elevated over the standard condition of $105^{\circ} \mathrm{C}$, which is used for R-F resin. The 4-methylresorcinol formaldehyde resin shows that increased temperature induces further condensation to occur within the resin without substantial increase in oxidation . to ketone and quinone structures. Indeed, the opposite trend is observed for those functionalities. However, R-F resin itself has essentially no ketone or quinone structures present when freshly prepared, in contrast to the 4-methylresorcinol polymer.

The issue of crosslinking of the 4-derivatized resins with respect to their performance is an area of great importance for future study. Currently, it has not been possible to prepare methyl deriviatives that will not dissolve in water and/or $2 \mathrm{MNaOH}$ solution. NMR studies indicate that the methyl materials are oligomeric and that addition of phenolic moieties, which can aid crosslinking, is warranted. However, the additional amounts of crosslinking phenolic required may cause serious reduction in either capacity or chemical stability of the resin, hence in the performance of these resins.

The $85 \%$ 4-fluororesorcinol/15\% phenol formaldehyde resin appears to have good stability in alkaline solution, but elemental analysis results suggest there may be some nucleophilic displacement reaction which occurs during synthesis. Further studies should focus on a more thorough examination and correlation of structure and performance for this material. The related halogen material, 4-chlororesorcinol, also appears to undergo a nucleophilic displacement reaction of the chlorine, to give an oxidized organic and free chloride ion. 



\subsection{References}

1. Hubler, T.L.; Franz, J.A.; Shaw, W.J.; Bryan, S.A.; Hallen, R.T.; Brown, G.N.; Bray, L.A.; Linehan, J.C., "Synthesis, Structural Characterization, and Performance Evaluation of ResorcinolFormaldehyde (R-F) Ion-Exchange Resin," PNL-10744, Pacific Northwest National Laboratory, Richland, Washington, August 1995.

2. a) "Cesium-Specific Phenolic Ion Exchange Resin," PCT Int. Appl WO 91,009,891 (11 July 1991; J.P. Bibler and R.M. Wallace to the U.S. Department of Energy); C.A. 115, 234200 (1991).

b) Pennington, L.D.; Williams, M.B. Ind. Eng. Chem. 1959, 6, 759.

3. Bray, L.A. PNL Test Procedure. "Determination of Batch Sorption Ratios for Ion-Exchange Materials Using Radionuclide Tracer Techniques," 1989, WTC-006-21-1.

4. "Hydrolysis of Toluene Diamines to Produce Methyl Resorcinols," U.S. 3,933,925 (January 20, 1976; N.P. Greco to Koppers Co., Inc.)

5. a)Belanger, P.C.; Lau, C.K.; Williams, H.W.R.; Dufresne, C.; Scheignetz, J. Can. J. Chem. 1988, 66, 1479. b) Patrick, T.B.; Darling, D.L. J. Org. Chem. 1989, 51, 3242.

6. Hudlicky, M; Bell, H.M. J. Fluorine Chem. 1974, 4, 19.

7. Duan, J.; Su, D.; Wu, J; Chen, Q. J. Fluorine Chem. 1994, 66, 167. 


\section{Distribution}

No. of

Copies

\section{OFFSITE}

2 DOE/Office of Scientific and Technical Information

J.P. Bibler

Westinghouse Savannah River Co.

Building 773-A

Aiken, SC 29802

J.M. Birmingham

Boulder Scientific Company

598 Third Street

Mead, CO 80542

Kurt Gerdes

DOE/Office of Technology Development

Trevion II Building

12800 Middlebrook Road

Germantown, MD 20874

2 Oak Ridge National Laboratory

MS 6273

P.O. Box 2008

Oak Ridge, TN 37831-6223

$$
\begin{aligned}
& \text { C.P. McGinnis } \\
& \text { R.D. Hunt }
\end{aligned}
$$

J.L. Swanson

1318 Cottonwood Drive

Richland, WA 99352

M.C. Thompson

Savannah River Technology Center

P.O. Box 616

Aiken, SC 29802
No. of

Copies

ONSITE

3 DOE Richland Operations Office
J.A. Frey
K8-50
J.P. Hanson
$\mathrm{K} 8-50$
R.A. Pressentin A6-54

12 Westinghouse Hanford Company

J.N: Appel

G3-21

S.A. Barker

R2-11

K.M. Eager

H5-27

R.R. Gadd

B4-49

K.A. Gasper

G3-21

R.A. Kirkbride

H5-27

M.J. Klem

H5-27

R.M. Orme

H5-27

D.L. Penwell

H5-27

I.E. Reep

G3-21

J.P. Sloughter

H5-27

D.J. Washenfelder

H5-27

41 Pacific Northwest National Laboratory

E.G. Baker

P8-38

W.F. Bonner

K9-14

K.P. Brooks

P7-43

G.N. Brown

P7-25

S.A. Bryan

P7-25

J.L. Buelt

P7-41

B.C. Bunker

$\mathrm{K} 2-45$

L.D. Carlson

$\mathrm{P} 7-25$

J.A. Franz

$\mathrm{K} 2-38$

R.T. Hallen

P8-38

T.R. Hart

K3-75

M.O. Hogan

P8-38

L.K. Holton

P7-43

T.L. Hubler (10)

P8-38

A.Y.Kim

$\mathrm{K} 2-44$

W.L.Kuhn

K2-21

Dist.1 
No. of

Copies

PNNL (contd)

D.E. Kurath - P7-43

J.P. LaFemina K2-25

J.C. Linehan K2-38

N.J. Lombardo K9-91

S.J. Ortiz P8-38

R.K. Quinn K9-69

K.R. Savard K9-04

L.J. Sealock K2-10

S.C. Slate K9-14

T.L. Stewart K9-91

J.M. Tingey P7-25

Technical Report Files (5) 